\title{
Cranioplasty with autologous cryopreserved bone after decompressive craniectomy. Complications and risk factors for developing surgical site infection
}

\author{
J. Sundseth • A. Sundseth • J. Berg-Johnsen • \\ W. Sorteberg $\cdot$ K.-F. Lindegaard
}

Received: 25 October 2013 / Accepted: 30 December 2013 /Published online: 4 February 2014

(C) The Author(s) 2014. This article is published with open access at Springerlink.com

\begin{abstract}
Background Renewed interest has developed in decompressive craniectomy, and improved survival is shown when this treatment is used after malignant middle cerebral artery infarction. The aim of this study was to investigate the frequency and possible risk factors for developing surgical site infection (SSI) after delayed cranioplasty using autologous, cryopreserved bone.

Methods This retrospective study included 74 consecutive patients treated with decompressive craniectomy during the time period May 1998 to October 2010 for various nontraumatic conditions causing increased intracranial pressure due to brain swelling. Complications were registered and patient data was analyzed in a search for predictive factors.

Results Fifty out of the 74 patients $(67.6 \%)$ survived and underwent delayed cranioplasty. Of these, 47 were eligible for analysis. Six patients $(12.8 \%)$ developed SSI following the replacement of autologous cryopreserved bone, whereas bone resorption occurred in two patients $(4.3 \%)$. No factors predicted a statistically significant rate of SSI, however, prolonged procedural time and cardiovascular comorbidity tended to increase the risk of SSI.

Conclusions SSI and bone flap resorption are the most frequent complications associated with the reimplantation of autologous cryopreserved bone after decompressive craniectomy.
\end{abstract}

J. Sundseth $(\bowtie) \cdot J$. Berg-Johnsen $\cdot$ W. Sorteberg $\cdot$ K.-F. Lindegaard Department of Neurosurgery, Oslo University Hospital Rikshospitalet, Postboks 4950, Nydalen, 0424 Oslo, Norway e-mail: jsundset@ous-hf.no

J. Sundseth · A. Sundseth · J. Berg-Johnsen - K.-F. Lindegaard Institute of Clinical Medicine, University of Oslo, Oslo, Norway

A. Sundseth

Department of Neurology, Medical Division, Akershus University Hospital, Lørenskog, Norway
Prolonged procedural time and cardiovascular comorbidity tend to increase the risk of SSI.

Keywords Cranioplasty · Craniectomy · Autologous · Cryopreserved $\cdot$ Surgical site infection $\cdot$ Complications

\section{Introduction}

Decompressive craniectomy is a lifesaving surgical procedure in acute brain swelling $[12,49]$. The technique was first described by Harvey Cushing in 1905 [10]. Common causes of acute brain swelling are malignant middle cerebral artery (MCA) infarction, aneurismal subarachnoid hemorrhage (aSAH), intracerebral hemorrhage (ICH), traumatic brain injury (TBI), acute subdural hematoma (ASDH), and reactive edema after intracranial surgery. The procedure was first introduced for MCA infarction in 1956 [44].

For those who survive, the cranial defect after decompressive craniectomy is usually reconstructed at a later point of time. Cranioplasty is performed for the following reasons: protection of the brain, restoration of the brain's hydrodynamic conditions [14, 29, 51, 52], and cosmetics. Cranioplasty can be performed by using autologous bone or patient-specific prostheses made of various alloplastic materials $[6,9,23,31]$. Autologous bone is often preferred to allograft due to its perfect match to the bony defect and low cost.

Surgical site infection (SSI), defined as infection resulting in surgical removal of the implanted bone, is a feared complication in delayed cranioplasty. This retrospective study was conducted to identify complications after cranioplasty with cryopreserved autologous bone and to search for possible risk factors associated with the development of SSI. 


\section{Material and methods}

\section{Patients}

The study includes all patients from over a period of 12.5 years (May 1998 to October 2010) that underwent (1) decompressive craniectomy for acute brain swelling, (2) cryopreservation of the removed bone flap, and (3) reimplantation of the bone flap at the Neurosurgical Department, Oslo University Hospital Rikshospitalet, Oslo, Norway. Rikshospitalet is a tertiary-level university hospital that does not manage trauma patients.

Patients who had their reimplanted cryopreserved bone flaps removed due to SSI or bone flap resorption later underwent a secondary cranioplasty using a prefabricated, patient-specific prosthesis made of porous, biocompatible polyethylene (Medpore biomaterial customized implant. Porex Surgical, Inc. 15 Dart Road, Newnan, GA 30265-1017 USA).

\section{Methods}

\section{Surgical procedures}

Decompressive craniectomy In the decompressive craniectomy procedure, a standard frontotemporoparietal hemicraniectomy was performed, whereupon the dura mater was opened in a stellate fashion. A dura substitute (NeuroPatch ${ }^{\circledR}$ Aesculap AG, Am Aesculap-Platz, 78532 Tuttlingen) was then placed over the cerebral cortex, and the opened dura was repositioned over the substitute. In the past few years, a second dura substitute was positioned between the dura and the temporal muscle in order to ease surgical dissection of the temporal muscle during cranioplasty. The subcutis and cutis were closed separately. Connective tissue and blood were removed from the bone flap. The flap was immediately thereafter washed in sterile $\mathrm{H}_{2} \mathrm{O}_{2}$ and $\mathrm{NaCl} 9 \mathrm{mg} / \mathrm{ml}$ dried with sterile gauze, packed in a two-layer sterile instrument pouch (3 M Health Care 9097 St. Paul, MN 55144-1000 USA), and placed in an ultra-low freezer (Forma Scientific Inc. SA mod. 925, 401 Mill Creek Rd, Marietta, $\mathrm{OH} 45750)$ at $-86^{\circ} \mathrm{C}$.

Primary cranioplasty At primary cranioplasty, the bone flap was retrieved from the freezer when the patient arrived in the operating theater and then was thawed at room temperature. The sterile instrument pouch was opened and the bone placed in sterile Gentamycin-/ $\mathrm{NaCl}$ solution. The cutis and subcutis were cut open corresponding to previous incisions and dissected from the cranium and the temporal muscle. The temporal muscle was carefully dissected from the dura, avoiding any CSF leak. The edges of the scull at the previous craniectomy site were trimmed using a drill and a diamond burr so that the cranium and the bone flap matched exactly. The bone was then put into place and fixed to the scull using a craniofix (B Braun Aesculap Tuttlingen Germany) and/or the Lorenz plating system (Biomet microfixation 1520 Tradeport Drive Jacksonville FL 32218-2480). The temporal muscle was reattached to the temporal bone with sutures against small, separate burr holes when it was straightforward in order to dissect the muscle. In cases where the muscle was adherent and difficult to release from the dura, the bone flap was replaced over the muscle. The selected method was dependent on the individual surgeon's choice. Eight different surgeons with varying levels of experience have performed the primary cranioplasty procedures on the patients in this study.

Secondary cranioplasty During secondary cranioplasty, the surgical procedure until adequate exposure of the cranial defect was performed as described during the primary cranioplasty. A prefabricated patient-specific prosthesis was trimmed and fitted to match the cranial vault exactly and fixed to the scull using the Lorenz plating system, as described previously by the authors [47].

\section{Data obtained from the patients' medical journals}

The following data were obtained retrospectively from the patients' medical journals: age, sex, smoking habits, previous medical history, etiology of the brain swelling leading to decompressive craniectomy, side of craniectomy, prophylactic antibiotic treatment, duration of the primary cranioplasty surgical procedure (minutes), subcutaneous drainage after cranioplasty, in-hospital infection, time from decompressive craniectomy to cranioplasty (days), and follow-up (months).

The complications recorded after cranioplasty were SSI, post-operative hematoma, and bone resorption resulting in repeat surgery.

\section{Ethical considerations}

This study is part of a retrospective follow-up trial on patients with MCA infarction, approved by the Regional Committee for Medical and Health Research Ethics, and the data protection official for research. The present analysis was separately evaluated by the Regional Committee for Medical and Health Research Ethics as a quality assurance of existing treatment, and an additional special committee approval was therefore not needed. The study was also approved by the data protection official for research.

Statistical analysis

Categorical variables are presented as absolute values and percentages. Continuous, normally distributed data are presented as means and standard deviations (SD). Between-group differences were determined by $\chi^{2}$ statistics or Fischer's exact tests, as appropriate, and unpaired two-sample $t$ tests. Time 
intervals are presented as medians and interquartile ranges (IQR), and between-group differences were analyzed using the Mann-Whitney $U$ test.

A $p$ value $<0.05$ was used as level of significance. All statistical analyses were performed using SPSS 18.0.

\section{Results}

Patient cohort

A total of 74 patients (38 females and 36 males) underwent decompressive craniectomy. Their mean age was 49 years (range 6-78 years). Craniectomy was performed due to MCA infarction in 47 patients (63.5\%), aSAH in 17 (23\%), ICH or ASDH in seven (9.5\%), and reactive brain edema following tumor surgery in three $(4.0 \%)$. The craniectomy was unilateral in 73 patients and bifrontal in one. Fifty out of 74 patients $(68.4 \%)$ survived and had their bone flap replaced at a later point of time. Three patients were foreign tourists who had their bone flap replaced 4 to 26 days after decompressive craniectomy (before repatriation to their home country). None of them developed SSI during the hospital stay in Oslo. All three were lost to follow-up.

Thus, 47 patients, 20 females and 27 males with a median age of 47.8 years (range 6-74 years) were eligible for analysis and included in the study. Among these, decompressive craniectomy was performed for the following reasons: MCA infarction in 31 patient $(66.0 \%)$, aSAH in $11(23.4 \%)$, ICH or ASDH in four $(8.5 \%)$, and reactive edema after tumor surgery in one $(2.1 \%)$. Clinical data of the 47 patients are presented in Table 1 . They were followed for a median of 41 months (range 2-155 months).

\section{Primary cranioplasty}

The median time from decompressive craniectomy to primary cranioplasty was 97 days (range 38-568 days). The median duration of the surgical procedure was $115 \mathrm{~min}$ (range 40-230 $\mathrm{min}$ ).

Two patients $(4.3 \%)$ underwent surgical removal of a postoperative epidural hematoma within $6 \mathrm{~h}$ after the cranioplasty. Their bone flaps were replaced immediately after evacuation of the hematoma. None of these two patients had a subcutaneous drainage placed in connection with the primary procedure.

SSI, bone resorption, and bone flap removal

Six patients (12.8\%) developed SSI following replacement of the autologous cryopreserved bone. The bone flaps were removed 5, 17, 39, 119, 164, and 729 days, respectively, after the primary cranioplasty. The pathogens found and assumed to be responsible for the infections were: E. coli after 5 days, Propionibacterium acnes after 39 and 119 days, Methicillinresistant Staphylococcus aureus after 164 days, and S. aureus after 17 and 729 days. Two of the six patients that developed SSI (P. acnes after 39 days and S. aureus after 17 days) had for unknown reasons not received prophylactic antibiotic treatment prior to replacement of their cryopreserved bone. However, there was no statistical significant difference in the rate of SSI among those who received prophylactic antibiotics and those who did not $(p=0.61)$ (Table 1).

All six patients that developed SSI were treated with antibiotics following antimicrobial susceptibility testing for 4 to 8 weeks after removal of the implanted bone.

Two patients, a 6-year-old boy and a 61-year-old woman, had their bone flaps removed due to bone resorption 1,645 and 1,000 days, respectively, after cranioplasty.

Seven of the eight patients who had their bone flaps removed later underwent a secondary cranioplasty using a patient-specific prosthesis made of porous, biocompatible polyethylene. The eighth patient died a few weeks before planned secondary cranioplasty. None of the patients developed SSI after the secondary cranioplasty.

\section{Patient groups and SSI resulting in bone flap removal}

The background characteristics for all patients $(n=47)$ and the groups with $(n=6)$ or without SSI $(n=41)$ are presented in Table 1. There was no statistical significant difference between the two groups in any of the variables. There was, however, a trend towards more cardiovascular disease (SSI in 4/6 [67\%] versus non-SSI in 10/41 [24\%]; $p=0.06$ ), and longer surgical procedure in the SSI group (median; SSI $148 \mathrm{~min}$ [IQR, 110-240 $\mathrm{min}$ ] versus non-SSI $114 \mathrm{~min}$ [IQR, 90-142 $\mathrm{min}] ; p^{2} 0.06$ ).

\section{Discussion}

In the present study, eight out of 47 patients who underwent decompressive craniectomy and primary cranioplasty with autologous cryopreserved bone had their replaced bone flap removed again later due to SSI (six patients) and bone resorption (two patients). In the SSI group, there was a trend toward longer surgical procedure and more cardiovascular disease. None of the patients developed SSI after secondary cranioplasty using patient-specific cranial prosthesis.

Preservation of bone flaps

Bone flaps removed during decompressive craniectomy are often preserved in a deep freezer, but the practice differs with regard to the freezing temperature used, ranging from $-16^{\circ} \mathrm{C}$ to $-84^{\circ} \mathrm{C}[2,25,26,34,37,42]$. Iwama et al. evaluated the 
Table 1 Background characteristics of 47 patients who underwent delayed cranioplasty
Values are $\mathrm{n}$ and (\%), unless indicated otherwise

${ }^{a}$ Known prior to craniectomy and considered stable disease: two patients with breast cancer, one with ovarian cancer, one with cervical cancer, and one with testicular cancer

${ }^{\mathrm{b}}$ Chronic obstructive pulmonary disease

${ }^{c}$ Pneumonia, urinary infection, sepsis, and infection without known focus requiring postoperative antibiotic treatment

\begin{tabular}{|c|c|c|c|c|}
\hline & All $n=47$ & SSI $n=6$ & Non-SSI $n=41$ & $P$ \\
\hline Age, mean (SD) & $47.8(13.1)$ & $48.2(13.4)$ & $47.7(13.3)$ & 0.94 \\
\hline Male sex & $27(57.4)$ & $4(66.7)$ & $23(56.1)$ & 1.00 \\
\hline Smoking & $12 / 39(30.8)$ & $2 / 5(40.0)$ & $10 / 34(29.4)$ & 0.63 \\
\hline \multicolumn{5}{|l|}{ Comorbidity } \\
\hline Diabetes & $5(10.6)$ & $1(16.7)$ & $4(9.8)$ & 0.51 \\
\hline Cancer $^{\mathrm{a}}$ & $5(10.6)$ & $0(0)$ & $5(12.2)$ & 1.00 \\
\hline $\mathrm{COPD}^{\mathrm{b}}$ & $3(6.4)$ & $0(0)$ & $3(7.3)$ & 1.00 \\
\hline Cardiovascular disease & $14(29.8)$ & $4(66.7)$ & $10(24.4)$ & 0.06 \\
\hline \multicolumn{5}{|l|}{ Cause of craniectomy } \\
\hline MCA infarction & $31(66.0)$ & $2(33.3)$ & $29(70.7)$ & 0.16 \\
\hline $\mathrm{SAH}$ & $11(23.4)$ & $3(50.0)$ & $8(19.5)$ & 0.13 \\
\hline Tumor cerebri & $1(2.1)$ & $1(16.7)$ & $0(0)$ & 0.13 \\
\hline $\mathrm{ICH} / \mathrm{ASDH}$ & $4(8.5)$ & $0(0)$ & $4(9.8)$ & 1.00 \\
\hline Right-sided & $28(59.6)$ & $2(33.3)$ & $26(63.4)$ & 0.20 \\
\hline In-hospital infection after craniectomy ${ }^{\mathrm{c}}$ & $40(85.1)$ & $5(83.3)$ & $35(85.4)$ & 1.00 \\
\hline $\begin{array}{l}\text { Time from craniectomy to cranioplasty in days, } \\
\text { median (IQR) }\end{array}$ & $97(82-120)$ & $94(74-164)$ & $101(83-121)$ & 0.70 \\
\hline Operation time in min, median (IQR) & $115(95-159)$ & $148(110-204)$ & $114(90-142)$ & 0.06 \\
\hline Prophylactic antibiotics & $36(76.6)$ & $4(66.7)$ & $32(78.0)$ & 0.61 \\
\hline Post-operative subcutaneous drainage & $16(34.0)$ & $3(50.0)$ & $13(31.7)$ & 0.40 \\
\hline
\end{tabular}

complication rates at different freezing temperatures $\left(-84{ }^{\circ} \mathrm{C}\right.$ versus $-35^{\circ} \mathrm{C}$ ). Among their 47 patients, one developed SSI and one experienced bone flap resorption, both occurring in the group with a storage temperature of $-35^{\circ} \mathrm{C}[26]$.

\section{Cranioplasty}

Although various alloplastic materials such as stainless steel mesh-acrylic [15], titanium [27, 46], methyl methachrylate [4, 5], and customized prefabricated prostheses [9, 11, 13, 16, 47] are available for cranioplasty, most surgeons prefer to use the patient's own bone whenever possible. A review of the most common mode of skull defect reconstruction in 25 major neurosurgical centers in Australia showed that $96 \%$ preferred the use of cryopreserved autologous bone [3]. The use of autologous bone has the advantages of an ideal geometrical fit. Also, bone flaps kept frozen for up to 19 months have been shown to have the capacity for revitalization through a process of revascularization, resorption, and accretion [42]. Oh et al. demonstrated that osteoblast-like cells can survive in frozen bone [39], which concurs with clinical, radiologic, and radionuclide studies indicating the same [22].

SSI after cranioplasty with cryopreserved bone

The use of cryopreserved autologous bone in the reconstruction of the cranial defect after craniectomy entails a risk for developing SSI. The infection rate varies between studies, from 0 to $25.9 \%$ with an average of $7.7 \%$ (Table 2) [2, 7, 19, 24-26, 32, 34-37, 42, 53].

At some institutions, the removed bone flaps are routinely examined for bacterial contamination prior to storage. Chiang et al. found that the frequency of SSI did not increase after reimplanting bone flaps contaminated with microorganisms such as P. acnes, coagulase-negative Staphylococci, and S. aureus [8]. However, the risk of SSI in the reimplantation of bone flaps with positive bacterial cultures prior to preservation has not been determined. The same pathogens mentioned above were involved in five out of six cases of SSI in our patients. We do not know if they were contaminated before cryopreservation, since bacteriological examination of the bone flap prior to preservation has not been implemented as routine in our department.

We did not find any statistically significant relationship between the time interval from decompressive craniectomy to primary cranioplasty and the risk of SSI. This is in accordance with several previous studies $[17,41,50]$, but in contrast with others, who have shown benefits from delaying the cranioplasty procedure [20, 43, 48]. However, we found a non-significant trend toward prolonged operation time being associated with an increased risk of SSI. This corresponds well with the findings in two recently published studies by $\mathrm{Kim} \mathrm{H}$ et al. and Lee et al. [28, 30], but contrasts with the results of Tokoro et al [48]. According to Manson et al., the risk of SSI increases from about $5 \%$ in routine primary cranioplasty to $14 \%$ during a second cranioplasty [33]. 
Table 2 Reported SSI in cranioplasty with autologous bone

$N / A$ indicates not available

\begin{tabular}{lllll}
\hline Author & $\mathrm{N}$ & Implant & Preservation & SSI \\
\hline Moreira-Gonzales et al. [35] & 312 & Autologous bone & N/A & $22(7.1 \%)$ \\
Matsuno et al. [34] & 54 & Autologous bone & Cryopreservation $-20{ }^{\circ} \mathrm{C}$ & $14(25.9 \%)$ \\
Iwama et al. [26] & 37 & Autologous bone & Cryopreservation $-35{ }^{\circ} \mathrm{C}$ & $1(2.7 \%)$ \\
& 12 & Autologous bone & Cryopreservation $-84{ }^{\circ} \mathrm{C}$ & $0(0 \%)$ \\
Inamasu et al. [25] & 31 & Autologous bone & Cryopreservation $-70{ }^{\circ} \mathrm{C}$ & $5(16.1 \%)$ \\
& 39 & Autologous bone & Subcutaneous pocket & $2(5.1 \%)$ \\
Huang et al. [24] & 151 & Autologous bone & Cryopreservation $-75{ }^{\circ} \mathrm{C}$ & $5(3.3 \%)$ \\
Lu et al. [32] & 16 & Autologous bone & Cryopreservation $-80{ }^{\circ} \mathrm{C}$ & $0(0 \%)$ \\
Cheng et al. [7] & 52 & Autologous bone & Cryopreservation $-?^{\circ} \mathrm{C}$ & $7(13.5 \%)$ \\
Grossmann et al. [19] & 12 & Autologous bone & Cryopreservation $-80{ }^{\circ} \mathrm{C}$ & $0(0 \%)$ \\
Prolo et al. [42] & 53 & Autologous bone & Cryopreservation $-20{ }^{\circ} \mathrm{C}$ & $2(3.7 \%)$ \\
Asano et al. [2] & 110 & Autologous bone & Cryopreservation $-40{ }^{\circ} \mathrm{C}$ & $5(4.5 \%)$ \\
Nagayama et al. [37] & 208 & Autologous bone & Cryopreservation $-16{ }^{\circ} \mathrm{C}$ & $8(3.88 \%)$ \\
Zingale et al. [53] & 21 & Autologous bone & Cryopreservation $-18{ }^{\circ} \mathrm{C}$ & $0(0)$ \\
\hline
\end{tabular}

None of our six patients developed SSI following secondary cranioplasty using patient-specific cranial prosthesis.

Prophylactic antibiotics were administered less often in the SSI group (67\%) compared to the non-SSI group (78 \%) in our study. The difference was, however, not statistically significant. Prophylactic antibiotics are not standard treatment in our department and are therefore dependent on the surgeon's preference. This is probably the reason why not all patients received prophylactic antibiotics.

In the present study, there was no association between the etiology of craniectomy and SSI following primary cranioplasty. Walcott et al. found, however, that stroke patients had a higher risk of SSI after cranioplasty than trauma patients [50], but no trauma patients were included in our study. Moreover, no statistically significant association was found between SSI and patient age, sex, prophylactic antibiotics or postoperative subcutaneous drainage. These findings correspond well with the results of Tokoro et al [48].

\section{Bone resorption after cranioplasty}

Several authors have reported on the risk factors for developing bone resorption following cranioplasty with autologous bone $[1,2,21,38,40,42]$. Hancock et al. found that 10 out of 12 sterilized, reimplanted bone flaps resorbed in children younger than 13 years [21]. Also, others have reported an increased risk of bone flap resorption in very young children $[40,42]$.

In our study, bone flap resorption occurred in a 6-year-old boy and in a 61-year-old woman 1,645 and 1,000 days, respectively, after cranioplasty. The follow-up period for all patients was median 41 months (range 2-155 months). One might suspect that a longer follow-up period in the present study could have revealed bone resorption in more patients.
However, Schuss et al. found in their study that $60 \%$ of bone flap resorption occurred within 1 year of follow-up and that no resorption was observed among patients followed for more than 5 years [45]. On the other hand, in a study by Grant et al. on patients younger than 19 years, bone resorption occurred in 20 out of 40 patients. Cranioplasty was performed with autologous bone following decompressive craniectomy and bone resorption occurred a mean 13.3 months (range 2-76 months) after primary cranioplasty [18].

Autoclaving the frozen bone before reimplantation in order to reduce the risk of SSI [1, 2, 21, 38, 40], along with shunt procedures [2] both seem to increase the risk of bone flap resorption.

\section{Limitations of our study}

Our study is a retrospective analysis and may suffer from anticipated deficiencies related to the loss of patient information. Various neurosurgeons with possibly differing operative techniques and assessments of indication for surgery, as well as the heterogeneous patient population may have influenced the study results. In addition, the small sample size precludes firm conclusions about the risk factors related to SSI.

\section{Conclusion}

SSI was the most common complication of the reimplantation of autologous cryopreserved bone after decompressive craniectomy seen in this study. Prolonged procedural time and cardiovascular comorbidity seemed to increase the risk of SSI. Because of the limited power of the study, it is, however, impossible to draw reliable conclusions, and further larger trials are required. 
Conflicts of interest The authors report no conflicts of interest concerning the materials or methods used in the present study or regarding the findings presented.

Open Access This article is distributed under the terms of the Creative Commons Attribution License which permits any use, distribution, and reproduction in any medium, provided the original author(s) and the source are credited.

\section{References}

1. Abbott KH (1953) Use of frozen cranial bone flaps for autogenous and homologous grafts in cranioplasty and spinal interbody fusion. $\mathrm{J}$ Neurosurg 10:380-388

2. Asano Y, Ryuke Y, Hasuo M, Simosawa S (1993) Cranioplasty using cryopreserved autogenous bone. No To Shinkei 45:1145-1150

3. Bhaskar IP, Zaw NN, Zheng M, Lee GY (2011) Bone flap storage following craniectomy: a survey of practices in major Australian neurosurgical centres. ANZ J Surg 81:137-141

4. Benzel EC, Thammavvaram K, Kesterson L (1990) The diagnosis of infections associated with acrylic cranioplasties. Neuroradiology 32 : 151-153

5. Blum KS, Schneider SJ, Rosenthal AD (1997) Methyl methacrylate cranioplasty in children: long-term results. Pediatr Neurosurg 26:33-35

6. Cabraja M, Klein M, Lehmann TN (2009) Long-term results following titanium cranioplasty of large skull defects. Neurosurg Focus 26: E10

7. Cheng YK, Weng HH, Yang JT, Lee MH, Wang TC, Chang CN (2008) Factors affecting graft infection after cranioplasty. J Clin Neurosci 15:1115-1119

8. Chiang HY, Steelman VM, Pottinger JM, Schlueter AJ, Diekema DJ, Greenlee JD, Howard MA 3rd, Herwaldt LA (2011) Clinical significance of positive cranial bone flap cultures and associated risk of surgical site infection after craniotomies and craniectomies. J Neurosurg 114:1746-1754

9. Couldwell WT, Chen TC, Weiss MH, Fukushima T, Dougherty W (1994) Cranioplasty with the Medpor porous polyethylene flexblock implant. Tech Note J Neurosurg 81:483-486

10. Cushing H (1905) The establishment of cerebral hernia as a decompressive measure for inaccessible brain tumors; with the description of intermuscular methods of making the bone defect in temporal and occipital regions. Surg Gynecol Obst 1:297-317

11. Dean D, Min KJ, Bond A (2003) Computer aided design of largeformat prefabricated cranial plates. J Craniofac Surg 14:819-832

12. Diedler J, Sykora M, Blatow M, Jüttler E, Unterberg A, Hacke W (2009) Decompressive surgery for severe brain edema. J Intensive Care Med 24:168-178

13. Eppley BL, Kilgo M, Coleman JJ 3rd (2002) Cranial reconstruction with computer-generated hard-tissue replacement patient-matched implants: indications, surgical technique, and long-term follow-up. Plast Reconstr Surg 109:864-871

14. Fodstad H, Love JA, Ekstedt J, Fridén H, Liliequist B (1984) Effect of cranioplasty on cerebrospinal fluid hydrodynamics in patients with the syndrome of the trephined. Acta Neurochir (Wien) 70:21-30

15. Galicich JH, Hovind KH (1967) Stainless steel mesh-acrylic cranioplasty. Tech Note J Neurosurg 27:376-378

16. Goh RC, Chang CN, Lin CL, Lo LJ (2010) Customiced fabricated implants after previous failed cranioplasty. J Plast Reconstr Aesthet Surg 63:1479-1484

17. Gooch MR, Gin GE, Kenning TJ, German JW (2009) Complications of cranioplasty following decompressive craniectomy: analysis of 62 cases. Neurosurg Focus 26:E9
18. Grant GA, Jolley M, Ellenbogen RG, Roberts TS, Gruss JR, Loeser JD (2004) Failure of autologous bone-assisted cranioplasty following decompressive craniectomy in children and adolescents. J Neurosurg 100:163-168

19. Grossmann N, Shemesh-Jan HS, Merkin V, Gideon M, Cohen A (2007) Deep-freeze preservation of cranial bones for future cranioplasty: nine years of experience in Soroka University Medical Center. Cell Tissue Bank 8:243-246

20. Hammon WM, Kempe LG (1971) Methyl methacrylate cranioplasty. 13 years experience with 417 patients. Acta Neurochir (Wien) 25:69-77

21. Hancock DO (1963) The fate of replaced bone flaps. J Neurosurg 20: 983-984

22. Hervás I, Floria LM, Bello P, Baquero MC, Peréz R, Barea J, Iglesias ME, Mateo A (2001) Microvascularized fibular graft for mandibular reconstruction: detection of viability by bone scintigraphy and SPECT. Clin Nucl Med 26:225-229

23. Hoffmann B, Sepehrnia A (2005) Tailored implants for alloplastic cranioplasty - clinical and surgical considerations. Acta Neurochir Suppl 93:127-129

24. Huang YH, Yang TM, Lee TC, Chen WF, Yang KY (2013) Acute autologous bone flap infection after cranioplasty for postinjury decompressive craniectomy. Injury 44:44-47

25. Inamasu J, Kuramae T, Nakatsukasa M (2010) Does difference in the storage method of bone flaps after decompressive craniectomy affect the incidence of surgical site infection after cranioplasty? Comparison between subcutaneous pocket and cryopreservation. J Trauma 68:183-187

26. Iwama T, Yamada J, Imai S, Shinoda J, Funakoshi T, Sakai N (2003) The use of frozen autogenous bone flaps in delayed cranioplasty revisited. Neurosurgery 52:591-596

27. Joffe J, Harris M, Kahugu F, Nicoll S, Linney A, Richards R (1999) A prospective study of computer-aided design and manufacture of titanium plate for cranioplasty and its clinical outcome. $\mathrm{Br} \mathrm{J}$ Neurosurg 13:576-580

28. Kim H, Sung SO, Kim SJ, Kim SR, Park IS, Jo KW (2013) Analysis of the factors affecting graft infection after cranioplasty. Acta Neurochir (Wien) 155:2171-2176

29. Kuo JR, Wang CC, Chio CC, Cheng TJ (2004) Neurological improvement after cranioplasty - analysis by transcranial doppler ultrasonography. J Clin Neurosci 11:486-489

30. Lee CH, Chung YS, Lee SH, Yang HJ, Son YJ (2012) Analysis of the factors influencing bone graft infection after cranioplasty. J Trauma Acute Care Surg 73:255-260

31. Lee SC, Wu CT, Lee ST, Chen PJ (2009) Cranioplasty using polymethyl methacrylate prostheses. J Clin Neurosci 16:56-63

32. Lu Y, Hui G, Liu F, Wang Z, Tang Y, Gao S (2012) Survival and regeneration of deep-freeze preserved autologous cranial bones after cranioplasty. Br J Neurosurg 26:216-221

33. Manson PN, Crawley WA, Hoopes JE (1986) Frontal cranioplasty: risk factors and choice of cranial vault reconstructive material. Plast Reconstr Surg 77:888-904

34. Matsuno A, Tanaka H, Iwamuro H, Takanashi S, Miyawaki S, Nakashima M, Nakaguchi H, Nagashima T (2006) Analyses of the factors influencing bone graft infection after delayed cranioplasty. Acta Neurochir (Wien) 148:535-540

35. Moreira-Gonzalez A, Jackson IT, Miyawaki T, Barakat K, DiNick V (2003) Clinical outcome in cranioplasty: critical review in long-term follow-up. J Craniofac Surg 14:144-153

36. Morina A, Kelmendi F, Morina Q, Dragusha S, Ahmeti F, Morina D, Gashi K (2011) Cranioplasty with subcutaneously preserved autologous bone grafts in abdominal wall-Experience with 75 cases in a post-war country Kosova. Surg Neurol Int 2:72

37. Nagayama K, Yoshikawa G, Somekawa K, Kohno M, Segawa H, Sano K, Shiokawa Y, Saito I (2002) Cranioplasty using the patient's autogenous bone preserved by freezing. An examination of postoperative infection rates. No Shinkei Geka 30:165-169 
38. Odom GL, Woodhall B, Wrenn FR Jr (1952) The use of refrigerated autogenous bone flaps for cranioplasty. J Neurosurg 9:606-610

39. Oh JH, Zöller JE, Kübler A (2002) A new bone banking technique to maintain osteoblast viability in frozen human iliac cancellous bone. Cryobiology 44:279-287

40. Ozaki F (1994) Clinical and experimental study for cranioplasty with autogenous frozen bone graft (in Japanese). J Wakayama Med Soc 45:217-225

41. Piedra MP, Ragel BT, Dogan A, Coppa ND, Delashaw JB (2013) Timing of cranioplasty after decompressive craniectomy for ischemic or hemorrhagic stroke. J Neurosurg 118:109-114

42. Prolo DJ, Burres KP, McLaughlin WT, Christensen AH (1979) Autogenous skull cranioplasty: fresh and preserved (frozen), with consideration of the cellular response. Neurosurgery 4:18-29

43. Rish BL, Dillon JD, Meirowsky AM, Caveness WF, Mohr JP, Kistler JP, Weiss GH (1979) Cranioplasty: a review of 1,030 cases of penetrating head injury. Neurosurgery 4:381-385

44. Scarcella G (1956) Encephalomalacia simulating the clinical and radiological aspects of brain tumor; a report of 6 cases. J Neurosurg $13: 278-292$

45. Schuss P, Vatter H, Oszvald A, Marquardt G, Imöhl L, Seifert V, Güresir E (2013) Bone lap resorption: risk factors for the development of a long-term complication following cranioplasty after decompressive craniectomy. J Neurotrauma 30:91-95

46. Stoodley MA, Abbott JR, Simpson DA (1996) Titanium cranioplasty using 3-D computer modelling of skull defects. J Clin Neurosci 3: $149-155$

47. Sundseth J, Berg-Johnsen J (2013) Prefabricated patient-matched cranial implants for reconstruction of large skull defects. J Cent Nerv Syst Dis 5:19-24

48. Tokoro K, Chiba Y, Tsubone K (1989) Late infection after cranioplasty-review of 14 cases. Neurol Med Chir (Tokyo) 29:196201

49. Vahedi K, Hofmeijer J, Juettler E, Vicaut E, George B, Algra A, Amelink GJ, Schmiedeck P, Schwab S, Rothwell PM, Bousser MG, van der Worp HB, Hacke W, for the DECIMAL, DESTINY, and HAMLET investigators, (2007) Early decompressive surgery in malignant infarction of the middle cerebral artery: a pooled analysis of three randomised controlled trials. Lancet Neurol 6:215-222
50. Walcott BP, Kwon CS, Sheth SA, Fehnel CR, Koffie RM, Asaad WF, Nahed BV, Coumans JV (2013) Predictors of cranioplasty complications in stroke and trauma patients. J Neurosurg 118:757-762

51. Winkler PA, Stummer W, Linke R, Krishnan KG, Tatsch K (2000) Influence of cranioplasty on postural blood flow regulation, cerebrovascular reserve capacity, and cerebral glucose metabolism. J Neurosurg 93:53-61

52. Won YD, Yoo DS, Kim KT, Kang SG, Lee SB, Kim DS, Hahn ST, Huh PW, Cho KS, Park CK (2008) Cranioplasty effect on the cerebral hemodynamics and cardiac function. Acta Neurochir Suppl 102:15-20

53. Zingale A, Albanese V (2003) Cryopreservation of autogenous bone flap in cranial surgical practice: what is the future? A grade B and evidence level 4 meta-analytic study. J Neurosurg Sci 47:137-139

\section{Comments}

This interesting retrospective analysis presents results of cranioplasty with autologous cryopreserved bone flaps after decompressive craniectomy in a diverse group of 47 patients. In this article, the authors evaluated the type and rate of complications and sought to answer the important question of whether there are any specific risk factors for developing surgical site infections (SSI). Although not statistically significant, it is interesting that both prolonged procedural time and cardiovascular comorbidity seem to increase the risk of SSI. However, if one analyzes the data in detail, several other factors such as smoking, diabetes, subarachnoid haemorrhage as the cause of craniectomy, avoidance of prophylactic antibiotics, and even insertion of subcutaneous drainages also may have influenced the incidence of SSI in the present series. The authors acknowledge the various limitations of the study, which are mainly the retrospective design and the small patient sample size. Further prospective analyses with larger cohorts will be needed, and hopefully may yield more concrete insight on this topic, may validate the findings provided, and may allow us to draw more definite conclusions.

Marcus Florian Oertel

Bern, Switzerland 